\title{
Gestão e competitividade: análise de um aglomerado produtivo moveleiro na Amazônia
}

Caio Rodrigo Alves Soares ${ }^{1}$; Heloíse Rodrigues Alves de Sá2; Marcos Rodrigues ${ }^{3}$; Selma Lopes Goulart ${ }^{4}$.

\begin{abstract}
Resumo
O objetivo deste trabalho foi caracterizar a organização do trabalho e decisões de produção no Polo Moveleiro em Parauapebas, Pará, verificando as condições de competitividade do aglomerado produtivo. Para a caracterização do polo moveleiro, foi realizada a coleta de dados primários, com a aplicação de questionários semiestruturados em 30 empreendimentos especializados na fabricação de móveis de madeira maciça. Através do questionário obteve-se dados quantitativos das principais espécies comercializadas no município, que permitiram a classificação das empresas instaladas no local, identificação das matérias-primas utilizadas pelo comerciantes e fabricantes de móveis, maquinário utilizado e o seu estado de conservação. Avaliou-se dados sobre o nível de qualificação dos funcionários empregados nos empreendimentos, os tipos de produtos fabricados, destinação dos resíduos da produção moveleira e possíveis acidentes de trabalho. Os resultados demonstram que, embora exista um conjunto de empresas que atuam no mesmo setor com potencial para crescimento, a falta de especialização e qualificação reduz a competitividade dos empresários locais, mantendo o setor e o aglomerado relativamente estagnado.
\end{abstract}

Palavras-chave: Desenvolvimento regional; Serraria; Especialização.

\footnotetext{
${ }^{1}$ Mestrando em Ciências Florestais pela Universidade Federal Rural da Amazônia, (UFRA). E-mail: caio.alves.soares@outlook.com

${ }^{2}$ Mestranda em Ciência e Tecnologia da Madeira pela Universidade Federal de Lavras, (UFLA). E-mail: heloise.sa@hotmail.com

${ }^{3}$ Professor na Universidade Federal Rural da Amazônia (UFRA) - Campus Parauapebas. Doutor em Desenvolvimento Socioambiental pela Universidade Federal do Pará (UFPA). E-mail: marcos.rodrigues.adm@gmail.com ORCID: http://orcid.org/0000-0003-3879-6115

${ }^{4}$ Professora na Universidade Federal Rural da Amazônia (UFRA)-Campus Parauapebas; Doutora em Ciência e Tecnologia da Madeira pela Universidade Federal de Lavras, (UFLA). E-mail: lopesgoulart@yahoo.com.br ORCID: https://orcid.org/0000-0002-1324-4931
} 


\title{
Management and competitiveness: furniture cluster analysis in the Amazon
}

\begin{abstract}
This study aimed to characterize labor organization and production decisions in a furniture cluster in Parauapebas, Pará, verifying the competitiveness conditions. For the characterization of the furniture cluster, primary data collection was performed with interviews using a semistructured questionnaire with 30 enterprises specialized in the manufacture of wood furniture. Through the questionnaire, quantitative data were obtained to identify the main species used in the municipality, allowing the classification of the companies involved in the cluster, identification of raw materials used by furniture manufacturers, machinery and their conservation conditions. Data about the level of employee's qualification, types of manufactured products, waste disposal from the furniture production and possible work accidents were evaluated. The results showed that although there are a significant amount of companies operating in the same sector with potential for growth, the lack of specialization and qualification reduces the competitiveness of local entrepreneurs, keeping the industry and the cluster relatively stagnant.
\end{abstract}

Keywords: Regional development; Sawmill, Specialization.

JEL: L68, R11, Q23.

\section{Introdução}

No sudeste da Amazônia, com a expansão da colonização no século XX e a grande disponibilidade de recursos naturais, orientou-se uma trajetória de especialização na cadeia produtiva madeireira (MERRY; AMACHER, 2005). Este movimento também levou a uma expansão da agropecuária e, consequentemente, do desmatamento (BARONA et al., 2010; MARGULIS, 2003; SIMMONS et al., 2007), colocando a Amazônia no centro do debate sobre sustentabilidade, incluindo os processos desenvolvidos pelas atividades empresariais e dos arranjos produtivos madeireiros na região, portanto para ampliar a competitividade requer-se além da qualidade do produto, padrões de responsabilidade social e sustentabilidade. 
Entretanto, na região de Carajás a mineração é o principal setor econômico (DINIZ et al., 2013), levando a uma reduzida atenção das políticas de incentivo ao desenvolvimento e da fiscalização sobre as atividades do setor moveleiro, sendo este um setor subaproveitado na região. Outras regiões, como o caso do arranjo produtivo do Alto Vale do Rio Negro em Santa Catarina (ATHERINO MACEDO; DIAZ MERINO; DALLAZEN CAMILLO, 2014), já demonstraram a importância que o setor moveleiro pode ter para a economia local quando este incorpora melhores condições de competitividade. A identificação do potencial de formação de aglomerados produtivos e incentivos para o setor moveleiro pode permitir às pequenas empresas alcançarem novos mercados, estabelecendo alternativas para o desenvolvimento regional.

Surge então o desafio para a cadeia produtiva da indústria moveleira no sudeste paraense desenvolver produtos e serviços com maior valor agregado, de forma sustentável e sem comprometer suas capacidades de inovação e gestão, elevando a competitividade do setor como um todo. Os resultados da melhoria dos processos e gestão são os ganhos de competitividade, como o caso da China (HAN; WEN; KANT, 2009), mas que ainda tem desafios a superar ou casos de um aumento da importação como os Estados Unidos (SCHULER; TAYLOR; ARAMAN, 2001), devido a um aumento da competitividade dos produtos dos outros países pela estagnação inovativa local.

Diante deste contexto, o objetivo deste trabalho foi caracterizar a organização do trabalho e decisões de produção no Polo Moveleiro em Parauapebas-PA, verificando as condições de competitividade do aglomerado produtivo. A hipótese estabelecida é que a grande disponibilidade de matérias-primas regionalmente fomentou a formação do aglomerado produtivo moveleiro, entretanto a reduzida fiscalização, conhecimento de gestão e baixa exigência do mercado consumidor reduzem a necessidade de inovação e a competitividade das empresas instaladas no local, necessitando que outros agentes incentivem o melhor desenvolvimento deste aglomerado produtivo.

\section{Competitividade e aglomerados produtivos: estratégias para o desenvolvimento regional}

As características produtivas de determinada região podem levar à especialização dos agentes econômicos em setores específicos e no conjunto de operações que decorrem deles. Para compreender a dinâmica e competitividade destes conjuntos produtivos é necessário desenvolver conceitos que permitam identificar os agentes envolvidos, o fluxo de operações que caracterizam a produção local e os mecanismos de coordenação entre eles. Dentre os conceitos destaca-se os Aglomerados Produtivos decorrente da concentração espacial de uma atividade produtiva (CAMPOS; GURGEL, 2016). 
Tais formações devem ser historicamente, culturalmente e economicamente construídos, levando a uma trajetória de aglomeração de empresas de determinado setor juntamente com demais agentes de suporte, transformação e apoio tecnológico. Tentativas de criar Arranjos Produtivos Locais (APLs) pode se mostrar falhas ou ineficientes quando as relações existentes não são fortes o suficiente para caracterizar o arranjo em questão, como o caso da apicultura em Mato Grosso, no qual a falta de vínculos entre os produtores e organizações não permitem ainda caracterizar tal atividade como um APL (DALLEMOLE et al., 2010).

A identificação de um conjunto de atividades desenvolvidas localmente e que movimentam uma cadeia produtiva é um passo para a formação de aglomerados produtivos. Entretanto a ideia principal dos aglomerados é elevar a competitividade deste setor para promover ganhos econômicos, sociais e ambientais regionalmente. Barbosa, Oliveira e Rezende (2010) fazem uma revisão abrangente do conceito de competitividade e colocam dois pontos fundamentais sobre este conceito: i) competitividade pode ser verificada com base na análise de eficiência das unidades de análise ; ii) a unidade de análise pode ser sistêmica, estrutural ou relacionada as organizações. Autores também enfatizam estes conceitos, mas colocam ressalvas quanto as limitações da análise de eficiência baseada apenas e receitas e custos, havendo um conjunto de fatores que levam a competitividade (MALDONADO GUZMAN, 2009).

Diniz Filho e Vicentini (2004) colocam que a competitividade não depende apenas de fatores microeconômicos, mas também do ambiente a qual as organizações estão inseridas. Desta forma, apenas a mudança de gestão e rotina dos processos é insuficiente para elevar a competitividade das empresas instalas em um local, as propostas de mudança cultural e macroeconômicas também influenciam na capacidade de inovação e elevação da competitividade.

O aproveitamento das potencialidades locais permite que as empresas possam formar aglomerados produtivos para ampliar sua eficiência produtiva através da redução de custos, dado a presença de outros agentes participantes do processo nas proximidades (ARAÚJO; NETO; SCHMITT, 2008); ter maior coordenação e capacidade de organização, inclusive com a formação de cooperativas (PEREIRA; SANTOS, 2013); e aproveitar a demanda local e nacional. Tal noção remete a ideia de que aglomerados produtivos criam condições para a elevação da competitividade das empresas envolvidas.

A existência de diversos atores que formam uma cadeia produtiva em torno de uma atividade leva que as ações de desenvolvimento regional considerem o aglomerado produtivo como um meio de inovação, competição e aprendizagem (SARACENI; ANDRADE JUNIOR, 2013). O desenvolvimento do aglomerado produtivo trilha sob uma constante evolução dos processos produtivos e da gestão, resultado em efeitos positivos regionais quando as inovações ampliam a competitividade dos agentes envolvidos. Sendo uma integração entre a localização espacial e as empresas envolvidas 
no processo, o aglomerado produtivo deve possuir uma governança consistente que promova o crescimento conjunto do setor.

Esses aglomerados têm como premissa a proximidade geográfica entre as empresas altamente especializadas, que desenvolvem redes e linkages com fornecedores, firmas subcontratadas e instituições de apoio. Nesse sentido, o setor e o território atuam como instâncias regulatórias importantes, definindo a governança como uma forma de coordenação do complexo industrial em sua base territorial (FUINI, 2012, p. 98).

A ampliação das demandas dos consumidores por ações sustentáveis tem alterado a forma de relação das organizações com o ambiente a que estão submetidas. Todescat, Moreira e Junior (2013) identificaram a importância da Responsabilidade Social Corporativa (RSC) em empresas pertencentes à aglomerados produtivos, mesmo sendo micro e pequenas empresas. Diversos são os indicadores que podem avaliar a RSC nas organizações, envolvendo desde a qualidade do produto e seu processo produtivo até as relações das organizações com os diversos interessados no processo produtivo (DE LARA, 2014).

A existência de uma cadeia de valorização dos produtos requer que as empresas adotem ações estratégicas de relação com a sociedade e o meio ambiente, consequentemente ampliando a competitividade do setor frente aos demais concorrentes. Reforça-se que em um aglomerado produtivo, as iniciativas devem ocorrer simultaneamente para todos agentes econômicos para manter a cadeia de produção funcional.

\section{Metodologia}

Esta pesquisa teve caráter exploratório, pois busca verificar quais os fatores ligados à competitividade do aglomerado produtivo moveleiro no município através do estudo de caso (YIN, 2009). Para realizar a caracterização do polo moveleiro foi realizada a coleta de dados primários com a aplicação de questionários semiestruturados com representantes de 30 empreendimentos especializados na fabricação de móveis de madeira maciça, no período de 09 a 27 de janeiro de 2017, em Parauapebas, Pará. A seleção da amostra se baseou em listagem fornecida pela cooperativa local com os empreendimentos regularizados, alguns dos responsáveis pelas empresas não estavam presentes no momento, o que limitou a amostragem. 
O questionário aplicado teve como objetivo realizar uma análise da competitividade das empresas através do levantamento quantitativo das principais espécies comercializadas no município, bem como realizar uma análise qualitativa a respeito da classificação das empresas instaladas no local, as formas de obtenção da matéria prima pelo comerciantes e fabricantes de móveis, dados a respeito do tipo de maquinário utilizado, bem como seu estado de conservação.

Foram aferidos também dados sobre o nível de qualificação dos funcionários empregados nos empreendimentos, os tipos de produtos fabricados, bem como a respeito da destinação dos resíduos da produção moveleira e possíveis acidentes de trabalho que já tiverem ocorrido. Os dados obtidos no questionário foram de maneira unicamente empírica, não sendo realizadas medições do quantitativo de madeira estocada nos pátios dos estabelecimentos.

Juntamente com a caracterização dos empreendimentos em termos do mercado moveleiro, relações de trabalho e processo produtivo, foi realizada uma discussão com a literatura existente sobre as práticas observadas e a capacidade de agregar valor à cadeia produtiva, orientando caminhos para tornar o aglomerado produtivo existente localmente em potencial estratégia de desenvolvimento sustentável.

\section{Resultados e Discussões}

\subsection{Mercado moveleiro}

As empresas entrevistadas foram classificadas por categorias de atividades, a saber: Serraria; Movelaria; Artesanato; Construção Civil; Carpintaria; Reforma e Pequenos Objetos de Madeira (P.O.M.). A tabela com a distribuição dos estabelecimentos por atividade realizadas no empreendimento, bem como a porcentagem de estabelecimentos que executam a atividade encontram-se na Tabela 1.

Tabela 1 - Divisão das empresas pesquisadas no Polo Moveleiro de Parauapebas, quanto a operação de beneficiamento de madeira realizada no empreendimento.

\begin{tabular}{lcc}
\hline Operações & $\mathbf{N}^{\mathbf{0}}$ de ocorrências & Frequência total (\%) \\
\hline Movelaria & 29 & 96,7 \\
Construção Civil & 16 & 53,3 \\
Carpintaria & 4 & 13,3 \\
Artesanato & 3 & 10 \\
Serraria & 2 & 6,7 \\
Reformas & 1 & 3,3 \\
P.O.M. & 1 & 3,3 \\
\hline
\end{tabular}

Fonte: Elaboração própria. 
Os dados apontam uma forte concentração das atividades no ramo de movelaria, com 96,67\% dos estabelecimentos exercendo algum tipo de atividade nesse ramo, porém de maneira descentralizada, de modo que em apenas $26,7 \%$ dos estabelecimentos, a produção é exclusivamente moveleira.

As empresas buscam diversificar sua produção, objetivando maiores lucros e abrangência no mercado. Contudo, essa diversificação exacerbada dos ramos de atuação nas empresas tem reflexo direto na qualidade do produto, tendo em vista que a falta de qualificação técnica para a produção de um determinado ramo acaba por prejudicar o bom desempenho do empreendimento em qualquer outro setor que a empresa realize atividades.

A falta de especialização dos empreendimentos é uma das características do setor moveleiro, em especial para as microempresas (LEÃO; NAVEIRO, 2009). Para a cadeia produtiva local examinada, a diversificação da produção apenas reduz a capacidade de agregar valor ao produto. A produção moveleira não explora seu potencial, a redução da renda empresarial é compensada com a diversificação produtiva, reduzindo a capacidade de agregação de valor e inovação produtiva como um todo.

Os 30 empreendimentos entrevistados para a realização deste trabalho empregam um total de 132 funcionários, com uma média de 3 a 4 funcionários por empreendimento. De acordo com o SEBRAE (2011), se o quadro de funcionários de uma empresa for menor que 19 funcionários, esta empresa classifica-se como microempresa, caso da totalidade das empresas instaladas.

Dos 30 comerciantes entrevistados, 19 deles possuem apenas o Ensino Fundamental, o que caracteriza mão de obra pouco escolarizada. A dificuldade de conciliar o tempo de trabalho com o tempo de estudos pode ser apontada como a causa da evasão escolar dos funcionários do setor, no município. Este problema é recorrente, uma vez que a maioria dos empreendimentos se localiza no mesmo local de residência dos proprietários, o que acaba por mesclar a rotina diária domiciliar com a jornada de trabalho.

\subsection{Condições de trabalho}

A fabricação de móveis é fundamentalmente exercida através de conhecimento adquirido empiricamente pelo funcionário ao longo de sua vida. A baixa qualificação técnica ainda é um problema para o desenvolvimento da indústria moveleira do município, uma vez que somente $26,8 \%$ da mão de obra empregada no setor possui algum tipo de qualificação para atuação com madeira. 
A falta de especialização da mão de obra do setor representa outro grande entrave para o desenvolvimento da indústria (GRZESZCZESZYN; MACHADO, 2010). A necessidade de treinamento dos funcionários do setor ainda não é uma realidade para os comerciantes e fabricantes da indústria moveleira no município. Apenas $50 \%$ dos entrevistados acreditam que é importante a qualificação da mão de obra empregada no setor moveleiro. Isto se deve pela existência de uma demanda local pouco exigente quanto as características do produto final e os métodos de produção empregados, inclusive quanto à origem da matéria-prima.

Dentre as atividades desenvolvidas no setor, 35,5\% dos empreendedores apontam o acabamento como a operação que demanda maior qualificação para os funcionários, uma vez que um acabamento de qualidade na peça produzida é fundamental para agregar valor de mercado ao produto. $\mathrm{O}$ corte das peças de madeira utilizadas na confecção dos móveis vem logo em seguida, com $26,5 \%$ de relato entre os comerciantes, conforme a Tabela 2.

Tabela 2 - Técnicas e operações de beneficiamento de madeira citadas pelos comerciantes e fabricantes de móveis instalados no Polo Moveleiro de Parauapebas, que possuem maior necessidade de treinamento.

\begin{tabular}{ll}
\hline Operações para treinamento & $\mathbf{( \% )}$ \\
\hline Acabamento do produto & 35,3 \\
Corte da madeira & 26,5 \\
Técnicas de produção de móveis & 14,7 \\
Operação das máquinas & 11,8 \\
Técnicas administrativas & 5,9 \\
Estudos sobre as espécies madeireiras & 2,9 \\
Segurança do Trabalho & 2,9 \\
\hline
\end{tabular}

Fonte: Elaboração própria.

É de suma importância que os funcionários do setor dominem as técnicas de corte, bem como, saibam manusear de maneira segura os implementos utilizados nas indústrias. A imperícia no manuseio de implementos é apontada como um dos principais fatores para a ocorrência de acidentes de trabalho no setor madeireiro, o que reforça a necessidade de treinamento da mão de obra. Dos 30 estabelecimentos visitados, 17 já registraram algum tipo de incidente com algum trabalhador, porém nenhum caso grave.

Quanto a segurança do trabalho no Polo Moveleiro, 90\% dos entrevistados nunca realizaram medição de ruído no ambiente de trabalho produzido pelas máquinas de beneficiamento de madeira. De acordo com a legislação vigente, os níveis de ruído permitidos para os trabalhadores não podem ser superiores a $85 \mathrm{~dB}$, durante uma jornada de trabalho de 8 horas. 
Para os implementos de beneficiamento de madeira mais encontrados durante a realização das visitas, as médias de emissão de ruído, segundo Venturoli et al (2003) são de 101,34dB para a serra circular; 96,24dB para tupia de mesa; 96,28dB para a plaina desempenadeira e de $89,55 \mathrm{~dB}$ para as lixadeiras. É importante ressaltar que os valores descritos pelo autor são de trabalhos realizados em fábricas de móveis onde a exposição dos trabalhadores era de no máximo 2 horas contínuas aos ruídos. Realidade bastante diferente da encontrada para os trabalhadores do Polo Moveleiro de Parauapebas, onde a média de exposição diária dos trabalhadores ao ambiente de emissão de ruídos é de 5 horas diárias.

Adequar o ambiente de trabalho no polo moveleiro em Parauapebas vai além apenas do cumprimento da legislação, evitando processos trabalhistas. Adotar práticas de responsabilidade social, com a preocupação com a qualidade do ambiente de trabalho e saúde do empregado, é capaz de promover ganhos significativos na produção. Ainda, a qualificação também é requerida para em conjunto com as condições dignas de trabalho propiciar a melhoria da qualidade do produto. Entretanto para alcançar estes objetivos requer-se maior atenção das instituições locais na prestação de apoio, tecendo novos caminhos para o aglomerado produtivo.

\subsection{Matéria-prima e processo produtivo}

De acordo com os dados levantados durante a realização da pesquisa, foi identificada utilização de 15 espécies na produção de móveis no Polo Moveleiro de Parauapebas, divididas em 15 gêneros e 8 famílias. As espécies estão designadas na Tabela 3, organizadas pelo nome popular, seguidas pelo nome científico, família botânica pertencente e o número de ocorrências de sua utilização entre os estabelecimentos

É importante salientar que todas as espécies identificadas são nativas do bioma amazônico, o que indica que o setor moveleiro do município ainda não demonstra interesse na utilização de madeiras exóticas como pinus, eucalipto e teca, uma vez que a oferta de madeira nativa consegue suprir as necessidades do mercado moveleiro local.

A família Fabaceae foi a que apresentou maior ocorrência, sendo 8 espécies divididas em seus respectivos gêneros botânicos. Contudo, é importante ressaltar que a família Anacardiaceae com apenas uma espécie ocorrente, a Muiracatiara (Astronium leicontei Ducke), correspondeu a $73,3 \%$ de todos os registros de utilização no Polo Moveleiro. 
Tabela 3 - Espécies madeireiras utilizadas nos processos produtivos do Polo Moveleiro de Parauapebas - PA.

\begin{tabular}{|c|c|c|c|}
\hline Espécie & Nome científico & Família botânica & Percentual de estabelecimentos \\
\hline Amarelão & Apuleia leiocarpa (Vogel) J. F. Macbr & Fabaceae & $23,3 \%$ \\
\hline Angelim-pedra & Hymenolobium modestum Ducke & Fabaceae & $63,3 \%$ \\
\hline Angico & Anadenanthera columbrina (Vell.) Brenan & Fabaceae & $40,0 \%$ \\
\hline Cabeça-de-arara & $\begin{array}{l}\text { Aspidosperma desmanthum Bent. Ex } \\
\text { Müll.Arg. }\end{array}$ & Apocynaceae & $3,3 \%$ \\
\hline Cedro & Cedrela odorata $\mathrm{L}$ & Meliaceae & $13,3 \%$ \\
\hline Cedrorana & Cedrelinga cateniformes (Ducke) Ducke & Fabaceae & $23,3 \%$ \\
\hline Cumarú & Dipteryx odorata (Aubl.) Willd. & Fabaeae & $13,3 \%$ \\
\hline Jatobá & Hymenaea courbaril $\mathrm{L}$. & Fabaceae & $20,0 \%$ \\
\hline Mangue & Trattinnickia rhoifolia Willd & Burseraceae & $3,3 \%$ \\
\hline Marupá & Simarouba amara Aubl. & Simaroubaceae & $36,7 \%$ \\
\hline Muiracatiara & Astronium leicontei Ducke & Anacardiaceae & $73,3 \%$ \\
\hline Orelha-de-macaco & Enterolobium schomburgkii (Benth.) Benth & Fabaceae & $3,3 \%$ \\
\hline Ipê-Amarelo & $\begin{array}{l}\text { Handroanthus impetiginosus (Mart. ex DC.) } \\
\text { Mattos }\end{array}$ & Bignoniaceae & $3,3 \%$ \\
\hline Tatajuba & Bagassa guianensis Aubl. & Moraceae & $46,7 \%$ \\
\hline Timborana & $\begin{array}{l}\text { Pseudopiptadenia suaveolens (Miq.) J.M. } \\
\text { Grimes }\end{array}$ & Fabaceae & $10,0 \%$ \\
\hline
\end{tabular}

Fonte: Elaboração própria.

Tal fator pode ser explicado pela consagrada utilização da Muiracatiara na fabricação de artigos de movelaria, tanto pela sua notória figura, característica muito apreciada pelos consumidores, quanto pela qualidade da madeira desta espécie, classificada como muito pesada $\left(\right.$ Densidade $=0.97 \mathrm{~g} / \mathrm{cm}^{3}$ ), o que a habilita a utilizações para fins estruturais, como vigas e cutelaria em geral (MAINIERI; CHIMELO; ALFONSO, 1983).

Os comerciantes realizam a identificação in loco e de maneira unicamente empírica, analisando características gerais da madeira como cor e cheiro. Estas características são duas das propriedades organolépticas mais importantes da madeira. Através da observação das propriedades organolépticas, os comerciantes atribuem o nome comercial pelo qual a madeira é comercializada na região. 
A compra de madeira pelos comerciantes do Polo Moveleiro de Parauapebas é majoritariamente realizada na região sudeste do Pará. O comercio de madeira é sempre realizado em $\mathrm{m}^{3}$, mesmo para as peças com menores dimensões. Os comerciantes adquirem as espécies madeireiras em forma de toras, pranchões, blocos ou "quadrados" como mostra a (Figura 1).

Figura 1 - Formas de aquisição de madeira para beneficiamento.

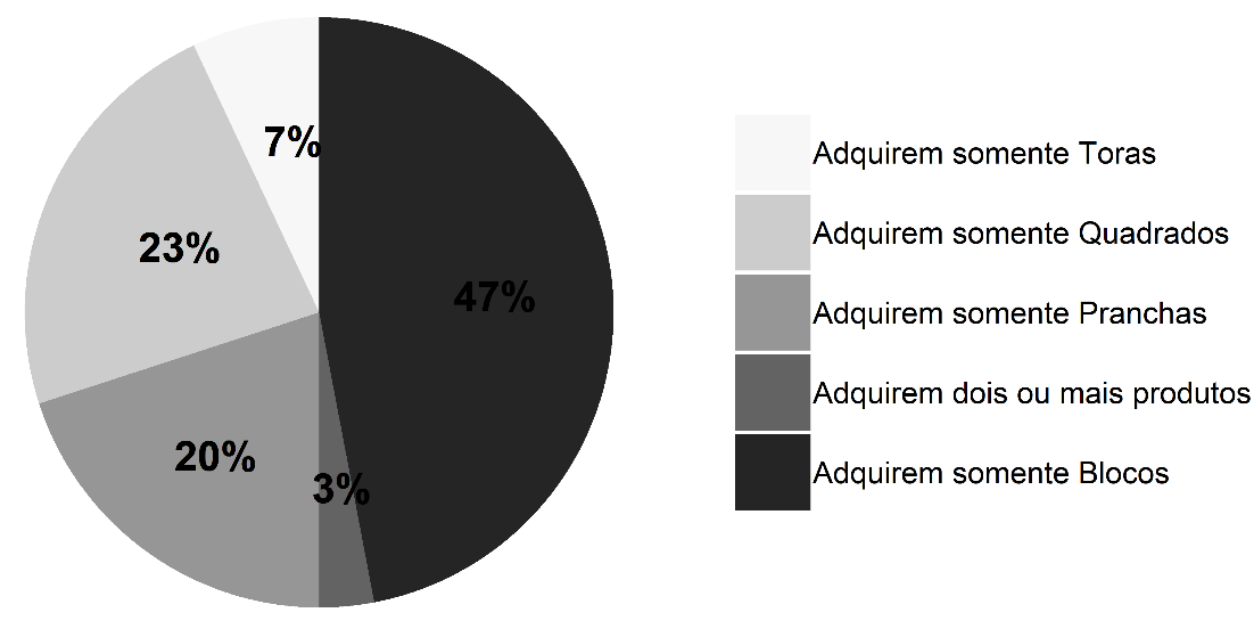

Fonte: Elaboração própria.

A procedência exata desta madeira é um grande problema para a cadeia de produção moveleira, uma vez que sem a informação precisa sobre o local de extração, bem como sobre a legalidade da madeira, a certificação florestal dos produtos produzidos no Polo Moveleiro torna-se impraticável, o que torna o mercado de móveis em Parauapebas pouco competitivo a nível nacional. A baixa qualificação e incentivo para o setor torna a mudança de práticas de gestão pouco provável no curto prazo, portanto o aglomerado produtivo tem poucas possibilidades de inovação e mudança.

Os resíduos, em especial a serragem, são vendidos por valores irrisórios aos ceramistas da região, que ao adquirirem o material, acabam prestando um serviço de limpeza das áreas dos fabricantes de móveis. Os valores giram em torno de $\mathrm{R} \$ 50,00$ por caminhão-caçamba completamente carregado de serragem, com uma média de volume de aproximadamente $5 \mathrm{~m}^{3}$. 
As pontas de peças, sobras do processo produtivo, são em sua maioria doadas para os pequenos carvoeiros da região. Uma alternativa apontada por autores como Dessbesell, Farias e Roesch (2017) é a utilização da serragem como fonte de biomassa para a geração de energia nos próprios empreendimentos, energia essa que pode ser aproveitada em processos produtivos da própria empresa, como para o aprimoramento de programas de secagem de madeira. Tais usos designados aos resíduos da indústria moveleira, apontam para um grande potencial de utilização alternativa dos resíduos gerados na cadeia produtiva de moveis e demais bens de consumo em madeira maciça.

O desenvolvimento de um aglomerado produtivo competitivo passa pela identificação dos diversos agentes a montante e a jusante do processo produtivo, os quais vão agregando valor ao produto. Neste caso, o uso econômico para os resíduos, além de reduzir o desperdício e gerar renda extra para os produtores de móveis, também fornece um uso sustentável para os resíduos gerados, cumprindo as normas sobre uso e destinação correta dos mesmos.

A produção de móveis em madeira maciça no município está concentrada na fabricação de bens de uso doméstico e duradouros, como camas mesas e guarda-roupas. Também foi constatada a presença de empresas especializadas na fabricação de móveis rústicos, que são móveis feitos de peças de madeira de grandes dimensões e maciças, utilizando-se até mesmo resíduos de serrarias, como costaneiras de grandes dimensões, para a montagem de mesas, bancos e cadeiras

A produção moveleira local é em sua totalidade consumida pelo mercado regional. Um dos fatores que pode explicar este fenômeno é o marketing negativo gerado pela falta de controle de cadeia de produção dos móveis no município. De acordo com Pimenta (2008), a certificação florestal é uma alternativa que pode além de expandir os horizontes de vendas dos comerciantes, agregar valor aos móveis fabricados no município.

\subsection{Competitividade}

A formação do aglomerado produtivo requer que os empresários locais desenvolvam estratégias de agregação de valor aos produtos (moveleiros) através da identificação correta de toda cadeia produtiva. A sustentabilidade do processo permitirá ampliar o mercado consumidor dos produtivos amazônicos, que podem ter alto valor agregado, ampliando a capacidade local de geração de emprego e renda. Isto requer o desenvolvimento de diversos mecanismos, inclusive com a criação de uma marca amazônica com a agregação de valor ao produto, o que elevaria a competitividade das empresas. A inovação voltada ao produto já demonstrou em outros trabalhos efeitos positivos em empresas ligadas a produção moveleira (OTERO-NEIRA; SCOZZI; LINDMAN, 2008). 
Para isto a certificação não apenas dos fabricantes de móveis, mas de todo o processo produtivo é necessário. A aquisição de matérias-primas provenientes de manejo florestal certificado é uma possibilidade que deve ser considerada pelos comerciantes.

Entretanto mesmo a certificação dos produtores de matérias-primas é um processo complexo pois podem haver dificuldades na obtenção dos registros (BASSO et al., 2011). Isto requer que as políticas em níveis estaduais compreendam a possibilidade de existir um APL no setor florestal, fomentando os agentes das diversas etapas da cadeia produtiva. Como colocado por Diniz Filho e Vicentini (2004), as mudanças macroeconômicas e culturais também influenciam na competitividade empresarial. $\mathrm{O}$ ambiente pouco exigência e a baixa capacidade de inovação das empresas localizadas no polo moveleiro também são obstáculos a serem superados, além apenas de variáveis microeconômicas.

O estudo demonstrou que mesmo sendo um aglomerado produtivo a capacidade de inovação ainda é muito baixa devido as características produtivas e de exigência do mercado, colocando entraves no desenvolvimento setorial e regional. Evidencia-se necessidade de articulação do polo moveleiro de Parauapebas com as organizações locais para elevar a competitividade.

Outros estudos já demonstraram que o envolvimento de diversos atores sociais pode fortalecer a cadeia produtiva moveleira (OLIVEIRA; FILOCREÃO, 2010). A baixa competitividade ocorre por processos produtivos que não garantem a certeza do resultado (como a forma de identificação da matéria-prima, que impacta em preços e no produto final), a baixa qualificação dos trabalhadores envolvidos, priorizando principalmente processos produtivos e pouco sobre a organização e segurança do trabalho, a falta de especialização (desempenho de atividades complementares a moveleira) e a baixa exigência do mercado local, que por sua vez pouco pressiona o aumento da competitividade do setor.

\section{Considerações Finais}

Este trabalho buscou caracterizar o ambiente no qual se insere o aglomerado produtivo moveleiro em Parauapebas, Pará e as condições de valoração do produto pelos processos utilizados. Verifica-se de fato um conjunto de pequenas empresas que atuam no mesmo setor e muito próximas de entre si, mas que devido ao baixo valor agregado ao produto acaba por desenvolver outras atividades correlacionadas à produção de móveis como forma de complementação de renda. Isto se deve por um conjunto de fatores, principalmente à falta de especialização de tais empresas, que, aliada a baixa importância dada à capacitação dos funcionários, melhoria das condições do ambiente de trabalho e às matérias-primas envolvidas no processo, atuam reduzindo a qualidade do produto, e consequentemente produzidos resultados negativos para a competitividade setorial. 
Entretanto, a disponibilidade histórica de matérias-primas na região (espécies madeireiras amazônicas) permitiu que o mercado local se desenvolvesse e incentivasse outros agentes da cadeia, formando um aglomerado produtivo local, mas com baixa competitividade. Para aproveitar o pleno potencial da atividade, requer-se que outros agentes atuem no processo de incentivo à inovação no aglomerado produtivo. Tal medida busca fortalecer o setor, principalmente com apoio de instituições locais e melhor coordenação entre os agentes integrantes da cadeia produtiva.

Para agregar valor ao produto, outras estratégias precisam ser desenvolvidas, como sugere-se com a criação de uma marca amazônica e a melhoria dos processos produtivos, principalmente quanto a identificação da matéria-prima. A demanda existente em outros mercados pode ser um alvo para tal aglomerado, que ainda precisa fortalecer para ser uma trajetória complementar para o desenvolvimento regional, ainda muito dependente da atividade mineradora.

\section{Referências}

ARAÚJO, C. M.; NETO, L. M.; SCHMITT, V. G. H. O processo de gestão da marca "vinho do porto": relevância da marca-país e dos aglomerados produtivos. Revista de Ciências da Administração, v. 10, n. 20, p. 184-196, 2008.

ATHERINO MACEDO, M.; DIAZ MERINO, E. A.; DALLAZEN CAMILLO, M. G. A gestão de design em arranjos produtivos locais (APL): o APL de móveis do planalto norte de Santa Catarina. Iberoamerican Journal of Industrial Engineering, v. 6, n. 12, p. 1-25, jul. 2014.

BARBOSA, L. G. M.; OLIVEIRA, C. T. F.; REZENDE, C. Competitiveness of tourist destinations: The study of 65 key destinations for the development of regional tourism. Revista de Administração Pública, v. 44, n. 5, p. 1067-1095, 2010.

BARONA, E. et al. The role of pasture and soybean in deforestation of the Brazilian Amazon. Environmental Research Letters, v. 5, n. 2, p. 024002, 2010.

BASSO, V. M. et al. Influência da certificação florestal no cumprimento da legislação ambiental e trabalhista na região amazônica. Acta Amazonica, v. 41, n. 1, p. 69-76, 2011.

CAMPOS, A. G.; GURGEL, A. DO M. Acidentes de trabalho graves e atividades produtivas nas regiões administrativas de saúde em Pernambuco: uma análise a partir da identificação de aglomerados produtivos locais. Revista Brasileira de Saúde Ocupacional, v. 46, n. 15, p. 1-12, 2016.

DALLEMOLE, D. et al. O Arranjo Produtivo Local da Apicultura de Mato Grosso: evolução recente e necessidades de ajuste. Revista de Estudos Sociais2, v. 24, n. 2, p. 181-197, 2010.

DE LARA, F. ANÁLISE BIBLIOGRÁFICA DOS INDICADORES DE SUSTENTABILIDADE E DE RESPONSABILIDADE SOCIAL CORPORATIVA. Revista Metropolitana de Sustentabilidade, v. 4, n. 3, p. 67-86, 2014. 
DESSBESELL, L.; FARIAS, J. A.; ROESCH, F. Fontes alternativas para energia em complementacao a lenha na Bacia Hidrografica do Rio Pardo, Brasil. Ciencia Rural, v. 47, n. 9, 2017.

DINIZ FILHO, L. L.; VICENTINI, Y. Teorias espaciais contemporâneas: o conceito de competitividade sistêmica e o paradigma da sustentabilidade ambiental. Desenvolvimento e Meio Ambiente, n. 9, p. 107-116, 2004.

DINIZ, F. H. et al. Livelihood strategies in settlement projects in the Brazilian Amazon: Determining drivers and factors within the Agrarian Reform Program. Journal of Rural Studies, v. 32, p. 196-207, 2013.

FUINI, L. L. Compreendendo a governança territorial e suas possibilidades: Arranjos Produtivos Locais (APL) e circuitos turísticos. Interações, v. 13, n. 1, p. 93-104, 2012.

GRZESZCZESZYN, G.; MACHADO, H. P. V. Políticas públicas para o desenvolvimento local: o caso de fomento às indústrias de móveis de Guarapuava, Paraná. Interações (Campo Grande), v. 11, n. 1, p. 81-92, 2010.

HAN, X.; WEN, Y.; KANT, S. The global competitiveness of the Chinese wooden furniture industry. Forest Policy and Economics, v. 11, n. 8, p. 561-569, 2009.

LEÃO, M. S.; NAVEIRO, R. M. Fatores de competitividade da indústria de móveis de madeira do Brasil. Disponível em: <http://www.abepro.org.br/biblioteca/ENEGEP1998_ART466.pdf>.

MAINIERI, C.; CHIMELO, J. P.; ALFONSO, V. A. Manual de identificação das principais madeiras comerciais brasileiras. São Paulo: Editora IPT, 1983.

MALDONADO GUZMAN, G. Worth and Competitiveness in Spain's Furniture Sector. Mercados y Negocios, v. 20, n. 10, p. 123-136, 2009.

MARGULIS, S. Causes of Deforestation of the Brazilian Amazon. Washington D.C.: [s.n.]. Disponível em: <http://elibrary.worldbank.org/doi/book/10.1596/0-8213-5691-7>.

MERRY, F. D.; AMACHER, G. S. Forest Taxes, Timber Concessions, and Policy Choices in the Amazon. Journal of Sustainable Forestry, v. 20, n. 2, p. 15-44, 20 abr. 2005.

OLIVEIRA, M. F. G.; FILOCREÃO, A. S. M. O arranjo produtivo local da madeira - móveis no município de Macapá/AP. Revista de Humanidades do Curso de Ciências Sociais da UNIFAP, v. 3, n. 3, p. 225-226, 2010.

OTERO-NEIRA, C.; SCOZZI, B.; LINDMAN, M. Low-tech, small- and medium-sized enterprises and the practice of new product development: An international comparison. European Business Review, v. 20, n. 1, p. 51-72, 18 jan. 2008.

PEREIRA, M. J. A.; SANTOS, A. R. V. Cooperativismo na Amazônia Setentrional: caminhos e descaminhos. Revista de Administração de Roraima, v. 1, n. 3, p. 187-210, 2013.

PIMENTA, A. C. Empresas madeireiras com certificação florestal e marketing verde: estratégias comunicacionais do grupo Cikel. 2008. 119 f. Tese (Mestrado) - Universidade Federal do Pará, Núcleo de Altos Estudos Amazônicos, Belém, 2008. Programa de PósGraduação em Desenvolvimento Sustentável do Trópico Úmido.

SARACENI, A. V.; ANDRADE JUNIOR, P. P. Proposta teórico-conceitual de desenvolvimento em arranjos produtivos locais. Gestão e Sociedade, v. 7, n. 16, p. 91-111, 2013.

SANTOS, I. R.; OLIVEIRA, A. C. "Protecionismo" Ambiental e Conflitos Sociais na Comunidade Bom Jesus, Uruará, Pará. Fragmentos de cultura, v. 25, n. 2, p. 213-222, 2015. 
SCHULER, A.; TAYLOR, R.; ARAMAN, P. A. Competitiveness of U.S. wood furniture manufacturers - Lessons learned from the softwood moulding industry. Forest Products Journal, v. 51, n. 7, p. 14-20, 2001.

SEBRAE. Anuário do trabalho na micro e pequena empresa - 2010/2011. Disponível em: $<$ http://www.sebrae.com.br/Sebrae/Portal Sebrae/Anexos/Anuario do Trabalho Na Micro e Pequena Empresa_2010_2011.pdf>.

SIMMONS, C. S. et al. The Amazon Land War in the South of Pará. Annals of the Association of American Geographers, v. 97, n. 3, p. 567-592, set. 2007.

TODESCAT, M.; MOREIRA, B. C. M.; JUNIOR, C. M. D. A utilização de indicadores de responsabilidade social para caracterização de aglomerados produtivos. Revista FACES Journal, v. 12, n. 4, p. 67-83, 2013.

VENTUROLI, F. et al. Avaliação do nível de ruído em marcenarias no Distrito Federal, Brasil. Revista Brasileira de Engenharia Agrícola e Ambiental, v. 7, n. 3, p. 547-551, 2003.

YIN, R. K. Case Study Research: Design and Methods. 4. Ed. SAGE Publications, 2009. 